Arch Virol (1990) 112: 195-202

Archives

Vírology

(C) by Springer-Verlag 1990

\title{
Characteristics of Parker's rat coronavirus (PRC) replicated in L-2 cells
}

\author{
D. H. Percy ${ }^{1}$, K. L. Williams ${ }^{1}$, S. J. Bond ${ }^{1}$, and J. I. MacInnes ${ }^{2}$ \\ Departments of ${ }^{1}$ Pathology and of ${ }^{2}$ Veterinary Microbiology and Immunology, \\ Ontario Veterinary College, University of Guelph, Guelph, Ontario, Canada
}

Accepted February 12, 1990

Summary. Parker's rat coronavirus (PRC) is a naturally-occurring viral infection of the laboratory rat. On the first passage, ATCC strain 8190 of PRC replicated in L-2 cells. Using the tenth passage of PRC in L-2 cells, the characteristics of the virus were compared with previous studies of sialodacryoadenitis virus (SDAV) replicated in L-2 cells. Based on light and immunofluorescence microscopic examination of control and inoculated cell cultures, PRC-associated $\mathrm{CPE}$ was frequently confined primarily to individual cells, and there were relatively few syncytial giant cells. Maximum titers were recovered at $36 \mathrm{~h}$ post inoculation (pi). Infectious virus was demonstrated at $\mathrm{pH}$ values ranging from 6.0 to 9.0 and a pH of 7.5 was determined to produce the highest titers of PRC. The optimum temperature for viral replication was $33^{\circ} \mathrm{C}$. Up to 15 passages of PRC in L-929 cells failed to produce detectable virus. However, after adaptation in L-2 cells (20th passage), PRC replicated to high titers in L-929 cells. Previously, in vitro studies of rat coronaviruses have been hampered by the lack of an identified continuous cell line to replicate these viruses in the laboratory. L-2 cells represent a readily-available continuous cell line that can support the replication of relatively high titers of PRC.

\section{Introduction}

Parker's rat coronavirus (PRC) and sialodacryoadenitis virus (SDAV) are two naturally-occurring coronaviruses in the laboratory rat that have been identified and partially characterized $[1,9]$. In the current literature they are associated with different patterns of disease. PRC is considered to produce a disease primarily of the respiratory tract $[2,9]$, while SDAV infections are associated with lesions of the salivary and lacrimal glands [7], and respiratory tract [13]. However, the viruses are closely related antigenically [1]. Thus conventional serological techniques do not serve to differentiate between the different rat coronaviral strains. Serological surveys indicate that the incidence of colonies positive for rat coronaviruses in a conventional setting may be over $50 \%[3$, 
8]. In the past, the characterization of rat coronaviruses has been hampered by the difficulties in replicating virus other than in primary rat kidney cells [1, 9]. Continuous cell lines have now been identified that will support the growth of SDAV [6, 10], and PRC [5]. In this communication, we report the successful cultivation of PRC in L-2 and L-929 cells, and the results of our studies on the characterization of this coronavirus in L-2 cells.

\section{Materials and methods}

\section{Cells}

The L-2 cell line, a subline of L-929 [12], was acquired from Dr. V. L. Morris (University of Western Ontario, London, Ontario). L-929 (of mouse origin) were obtained from The American Type Culture Collection (Rockville, MD). Cells were grown in Eagle's minimal essential medium (Gibco/BRL Inc., Burlington, Ontario) containing $200 \mathrm{U} / \mathrm{ml}$ penicillin, $80 \mu \mathrm{g} / \mathrm{ml}$ streptomycin, $0.025 \mu \mathrm{g} / \mathrm{ml}$ of gentamycin supplemented with $5 \%$ fetal bovine serum. Cells were propagated on $100 \times 15 \mathrm{~mm}$ Nunc polystyrene tissue culture dishes (Gibco/ $\mathrm{BRL}$ Inc.) at $37^{\circ} \mathrm{C}$ (unless otherwise stated) in a humidified atmosphere containing $5 \%$ $\mathrm{CO}_{2}$.

\section{Virus}

Parker's rat coronavirus (ATCCVR-635, Strain 8190) was obtained from the American Type Culture Collection (Rockville, MD). The virus was thawed, and reconstituted with $10 \mathrm{ml}$ of Eagle's MEM, then $1 \mathrm{ml}$ was inoculated onto L-2 cells. Parker's rat coronavirus (PRC) was allowed to adsorb for $1 \mathrm{~h}$, then monolayers were washed, and culture medium was replaced. Inoculated and control cultures were then incubated, and examined regularly for CPE.

\section{Viral infection}

Monolayers of L-2 and L-929 cells were grown until approximately $80 \%$ confluent, then inoculated with $1.0 \mathrm{ml}$ of stock virus suspension or infected cell culture supernatant. Virus was allowed to adsorb for one hour, then monolayers were washed and the culture medium replaced. Mock infected and inoculated cell cultures were then incubated at $37^{\circ} \mathrm{C}$ and $5 \%$ $\mathrm{CO}_{2}$ for $48-72 \mathrm{~h}$. Ten-fold serial dilutions of virus were made in cell culture medium and used to inoculate L-2 or L-929 cells. Replicate cultures were then fixed and examined by immunofluorescence microscopy as described below. The demonstration of viral antigen in $50 \%$ of inoculated cultures was interpreted to be the $\mathrm{TCID}_{50}$.

In PRC-inoculated L-929 cells, serial passage was performed, using cell culture fluid from inoculated cultures collected at $48-72 \mathrm{~h}$ post inoculation. Fifteen passages were performed in this manner. In addition, L-929 cells were inoculated with culture fluid from the 14th and 20th passage of PRC replicated in L-2 cells. Inoculated and control cells were examined for CPE and viral antigen as described below.

\section{Microscopy}

For light microscopy, control and infected cell cultures were fixed in methanol, and stained by the Giemsa method. Tissues for immunofluorescence microscopy were fixed in methanol, and incubated with antiserum from SDAV-infected rats, and identified with fluoresceinlabelled goat anti-rat IgG (Antibodies Incorporated, Davis, CA). 


\section{Kinetics of $P R C$ replication}

Using an incubation temperature of $37^{\circ} \mathrm{C}$, the time course for the production of infectious virus was determined. Replicate cell cultures were inoculated with approximately $10^{4.0}$ $\mathrm{TCID}_{50}$ of the 10th pass of PRC in L-2 cells. Infected cells were collected at $12 \mathrm{~h}$ intervals for up to $84 \mathrm{~h}$ post inoculation. Viral titers at each time point were determined as described above.

\section{Determination of optimum temperature and $\mathrm{pH}$}

For the evaluation of optimum $\mathrm{pH}$ for PRC replication in L-2 cells, following inoculation with virus, replicate cultures were maintained in culture medium adjusted with sterile sodium bicarbonate to $\mathrm{pH} 6.0,7.0,7.5,8.0$, and 9.0. For the determination of optimum temperature for viral replication, replicate cultures of L-2 cells inoculated with the 10th pass of PRC were incubated at $31,33,35,37$, and $39^{\circ} \mathrm{C}$ for $48-72 \mathrm{~h}$.

\section{Results}

\section{Replication in L-2 or L-929 cells}

Infectious virus and viral antigen were observed on the first passage of stock virus in L-2 cells. In virus-infected cells, viral antigen and early evidence of CPE were observed as early as $12 \mathrm{~h}$ post inoculation. In Giemsa-stained preparations of PRC-inoculated cells, degeneration of individuals cells, and scattered syncytial giant cells were observed, particularly in monolayers examined at 24
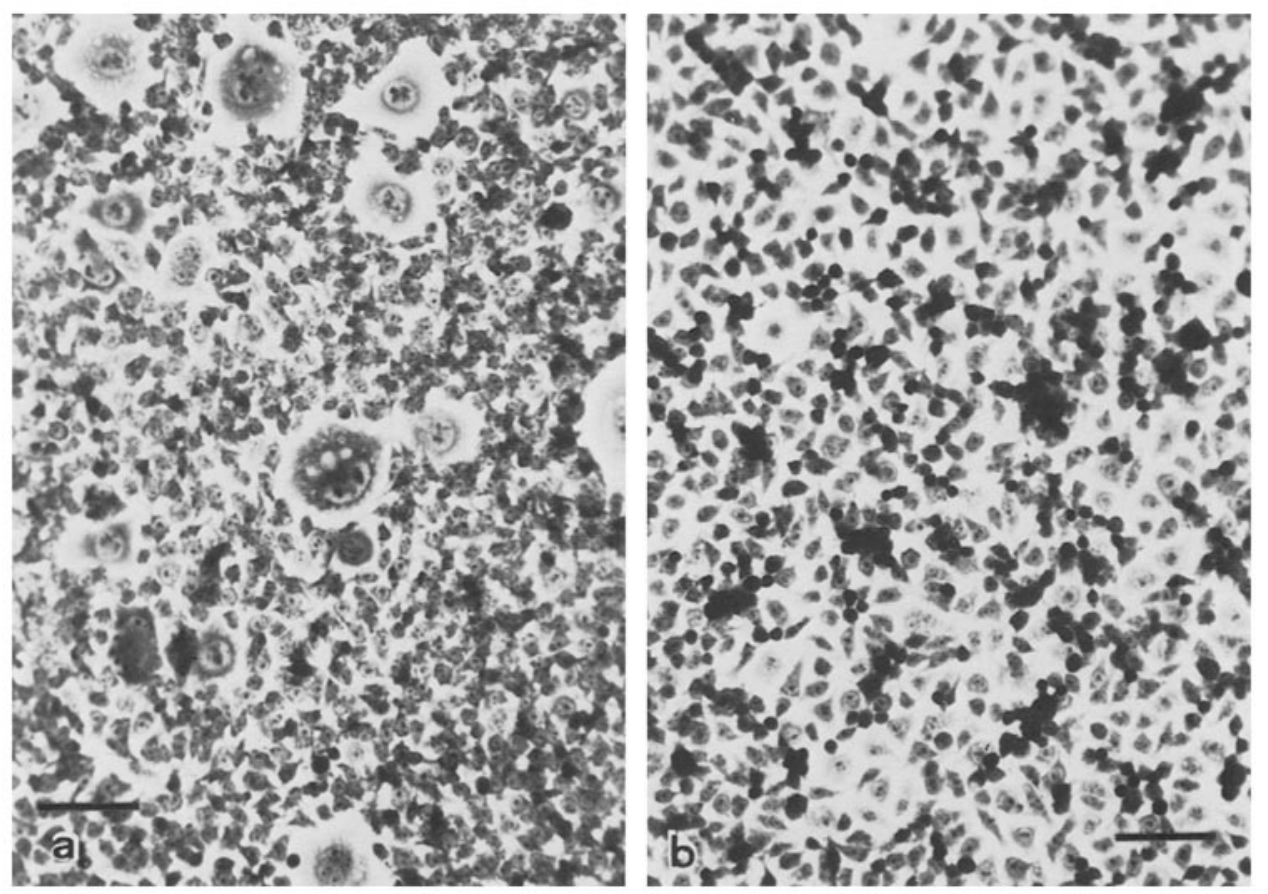

Fig. 1. a Control monolayer culture of non-inoculated L-2 cells. Giemsa stain. b Monolayer at $48 \mathrm{~h}$ after inoculation with the tenth pass of Parker's rat coronavirus (PRC) grown in L-2 cells. Note the pyknosis of individual cells, and the sparse numbers of syncytial cells. 


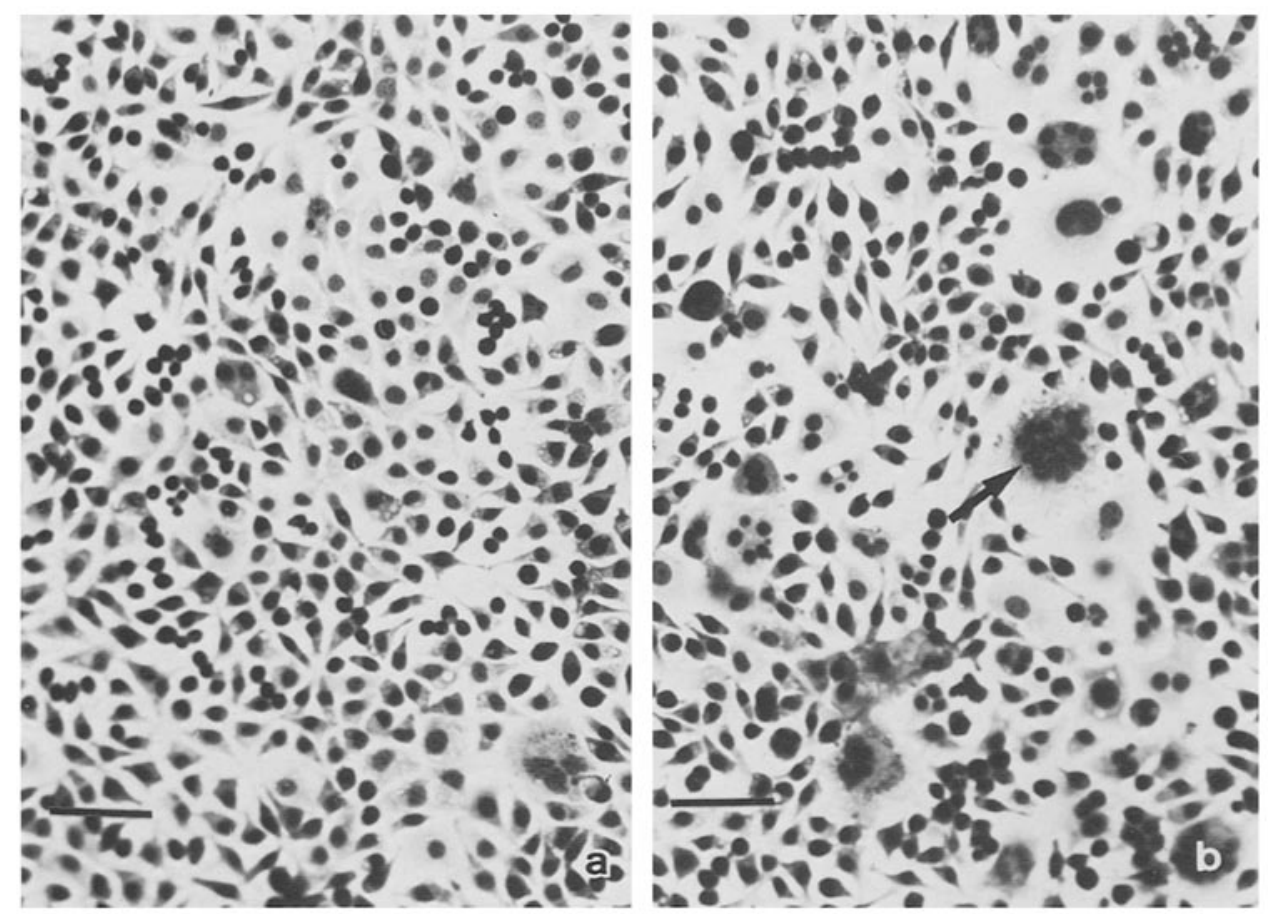

Fig. 2. a Control monolayer culture of control L-929 cells. b PRC-inoculated monolayer of L-929 cells $48 \mathrm{~h}$ after inoculation with cell culture fluid from the 35 th pass in L-2 cells. There are numerous densely-stained cells scattered in the infected cell sheet and a few syncytial giant cells (arrow). Giemsa stain. Bars: $20 \mu \mathrm{m}$

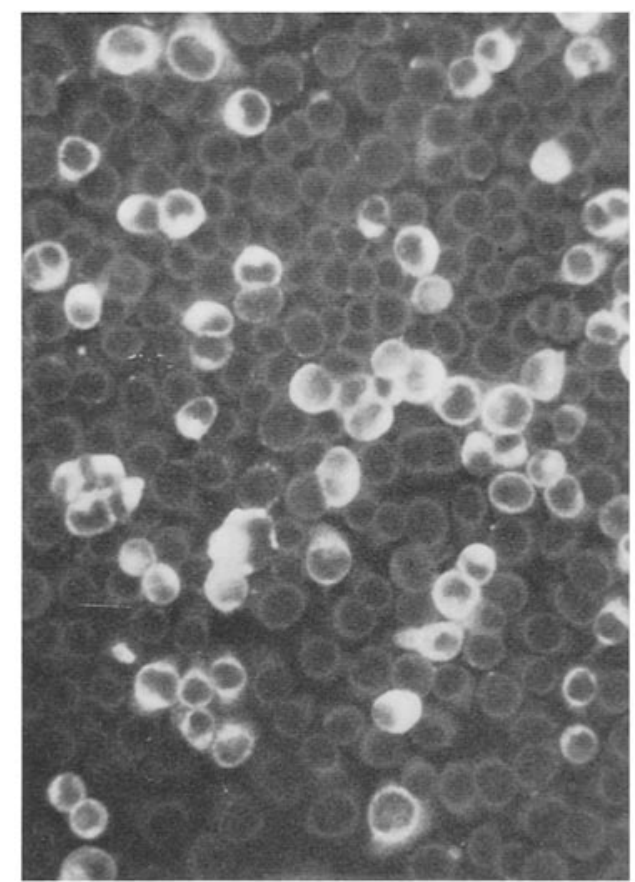

Fig. 3. Immunofluorescent microscopy preparation for the demonstration of viral antigen in PRC-infected L-2 cells examined at $48 \mathrm{~h}$ post-infection. There is marked cytoplasmic fluorescence primarily in individual cells. $\times 250$ 


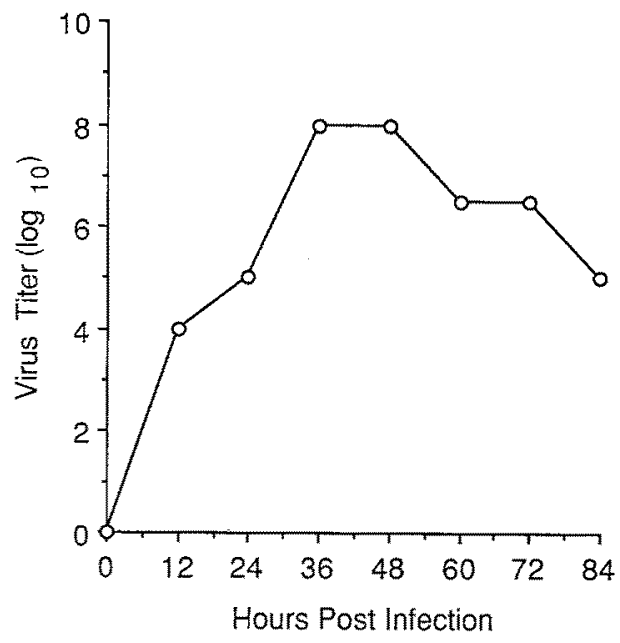

Fig. 4. Comparison of viral titers of PRC in L-2 cells when collected at $12 \mathrm{~h}$ intervals post inoculation. Virus titers are expressed in $\mathrm{TCID}_{50} / 1.0 \mathrm{ml}$

or more $h$ post inoculation. Densely-stained cells compatible with cell degeneration were the most consistent finding (Fig. 1). In monolayers with advanced CPE, there was destruction of the cell sheet, with separation of infected cells from the substrate. Following the inoculation of L-929 cells with stock virus, neither CPE nor viral antigen were detected after up to 15 serial passages. In attempts to replicate PRC in L-929 cells after replication in L-2 cells, viral antigen and CPE were not demonstrated following the 14th passage in L-2 cells, but were evident in L-929 cells after the 20 th passage in L-2 cells. In Giemsastained L-929 cells infected with PRC with evidence of CPE, there were minimal numbers of syncytial cells, and relatively large numbers of densely-stained cells consistent with cellular degeneration (Fig. 2). In virus-infected L-2 or L-929 cells stained for immunofluorescence microscopy, there was marked intracytoplasmic fluorescence of individual cells, with relatively sparse numbers of syncytial giant cells containing viral antigen in the cell cytoplasm (Fig. 3).

\section{Kinetics of $P R C$ replication in $L-2$ cells}

At $12 \mathrm{~h}$ post inoculation, titers of virus were approximately $10^{3.0} \mathrm{TCID}_{50} / \mathrm{ml}$. Titers peaked at $36 \mathrm{~h}$ post inoculation $\left(10^{8.0} \mathrm{TCID}_{50}\right)$, and fell to approximately $10^{4.0} \mathrm{TCID}_{50} / \mathrm{ml}$ at $84 \mathrm{~h}$ (Fig. 4).

\section{Optimal growth conditions}

Optimal titers of PRC were obtained in $\mathrm{L}-2$ cells at a $\mathrm{pH}$ of 7.5. However, infectious virus was detected at a pH ranging from 6.0 to 9.0 (Fig. 5). In a study of the range of temperatures which would support viral replication, PRC was demonstrated at temperatures of $31-37^{\circ} \mathrm{C}$. The highest titer of virus was obtained in L-2 cells incubated at $33^{\circ} \mathrm{C}$ (Fig. 6). 


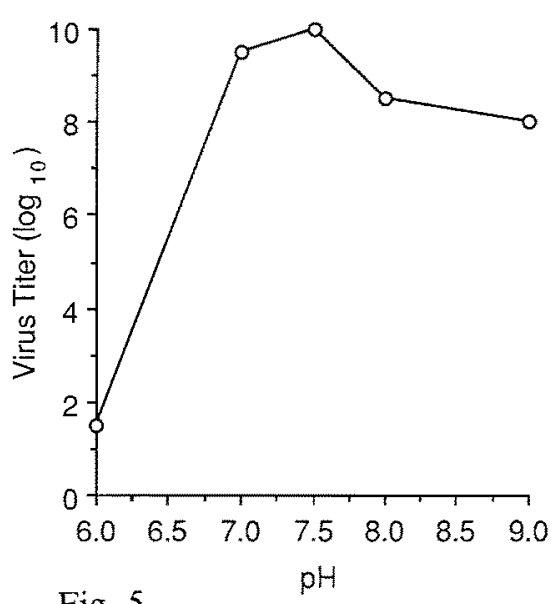

Fig. 5

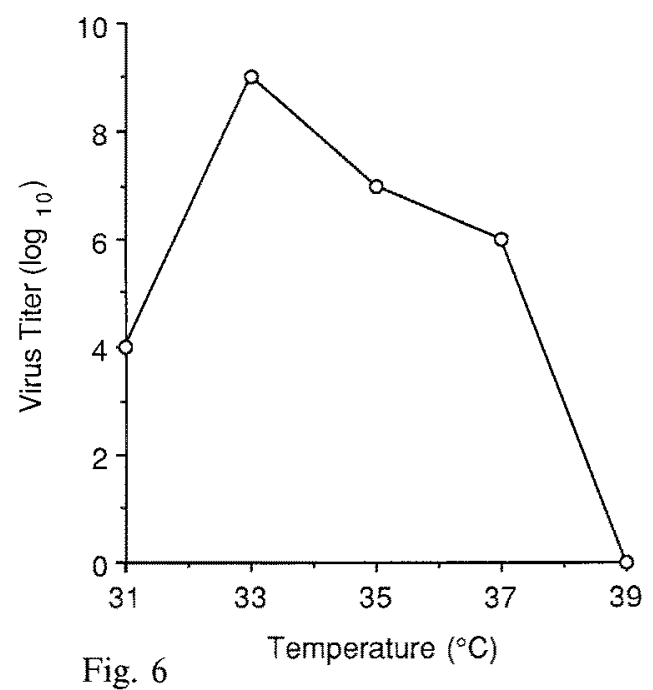

Fig. 6

Fig. 5. Comparison of titers of PRC when virus-infected $\mathrm{L}-2$ cells were incubated at $37^{\circ} \mathrm{C}$ at different $\mathrm{pH}$. Titers are expressed in $\mathrm{TCID}_{50} / \mathrm{ml}$

Fig. 6. Comparison of titers of PRC when virus-infected L-2 cells were incubated at different temperatures and tested after $48 \mathrm{~h}$. Titers are expressed in $\mathrm{TCID}_{50} / \mathrm{ml}$

\section{Discussion}

Although previous studies have revealed that PRC and SDAV are closely related antigenically [1], it is evident that the properties of the two viruses differ in some respects in their in vitro cultural characteristics. For example, in PRCinfected L-2 cells, fewer syncytial cells were evident both in Giemsa-stained preparations and in positive cultures stained by immunofluorescence microscopy. In SDAV-infected L-2 cells, syncytial giant cell formation was an important feature of the virus-associated change [10]. In a comparison of the kinetics of viral replication in PRC and SDAV, with both strains, peak viral titers were reached at 36-48 h pi (Fig. 4) [10]. Although the optimal $\mathrm{pH}$ for viral replication was observed to be 7.5 in both viruses, PRC was shown to replicate to relatively high titers over a wider $\mathrm{pH}$ range $(\mathrm{pH} 7-9)$ than does SDAV [10]. Optimal temperatures for viral replication were different in the two strains of rat coronavirus. Whereas previous studies revealed that SDAV replicated best at $37^{\circ} \mathrm{C}$ [10], the optimal temperature for the replication of PRC in vitro was $33^{\circ} \mathrm{C}$. Replication was more than 2 logs lower at $31^{\circ} \mathrm{C}$, and lower by one $\log$ at $37^{\circ} \mathrm{C}$ (Fig. 6). This finding is consistent with previous observations that PRC is primarily a disease of the respiratory tract in the naturally-occurring and experimentally-induced disease $[2,9]$. The lower optimum temperature for PRC replication in vitro may reflect the ability of the virus to replicate readily at a cooler site in the body, the upper respiratory tract. However, lesions were observed in the salivary and lacrimal glands in Wistar rats inoculated with $\mathrm{PRC}$ replicated in $\mathrm{L}-2$ cells at $37^{\circ} \mathrm{C}$ [11]. 
Previous in vitro characterization studies of the known rat coronaviruses have been hampered by the lack of a readily available continuous cell line to replicate PRC or SDAV in vitro. The reports of the successful replication of PRC and SDAV in a continuous cell line of rat mammary gland origin, LBC $[5,6]$, represented an important contribution to facilitate the replication of these viruses in the laboratory. However, the LBC cell line is not readily available, and in our laboratory, the L-2 cell line has replicated higher titers of virus than LBC cells. The demonstrated ability of both L-2 and L-929 cells to support the replication of PRC should facilitate additional studies on the characterization of these viruses. L-2 cells are a subline of L-929 cells. This cell line was developed from a primary strain of fibroblasts obtained from an adult mouse of the $\mathrm{C} 3 \mathrm{H}$ strain [4]. In a previous karyologic study of several sublines of L929 cells, there were marked chromosomal variations between individual lines [12]. In addition, there is some evidence that the properties of L-2 cell lines maintained in different laboratories may vary in some respects. For example, although the line of L-2 cells used in our studies will readily replicate SDA virus in our facility and in other laboratories, not all L-2 cell lines have proven capable of replicating SDA virus (Smith, A. L., Yale School of Medicine, New Haven, CT, and Holmes, K.V., Uniformed Services, University of the Health Sciences, Bethesda, MD, pers. comm.).

The ability of PRC to replicate in Earl's clone L-929 cells after serial passage is another indication of the degree of adaptation of the virus which may take place over time in vitro. Cell-virus receptor sites may be a critical factor in this adaptation process, but the mechanisms involved in this change are currently unknown. This aspect warrants further investigation. It may be possible to identify specific changes in viral proteins and/or nucleic acid composition of PRC which permits adaptation and subsequent replication in L-929 cells. The identification and characterization of such changes should provide additional information on the adaptation process associated with the replication of certain coronavirus in vitro.

\section{Acknowledgements}

This work was supported by a Natural Sciences and Engineering Research Council grant \#A0071 to D. H. Percy, and a University of Guelph Research Board grant to J. I. MacInnes.

\section{References}

1. Bhatt PN, Percy DH, Jonas AM (1972) Characterization of the virus of sialodacryoadenitis in rats: a member of the coronavirus group. J Infect Dis 126: 123-130

2. Bhatt PN, Jacoby RO (1977) Experimental infection of adult axenic rats with Parker's rat coronavirus. Arch Virol 54: 345-352

3. Caseboldt DB, Lindsey JR, Cassell GH (1988) Prevalence rates of infectious agents among commercial breeding populations of rats and mice. Lab Anim Sci 38: 327-329

4. Earl WR (1943) Production of Malignancy in vitro. IV. The mouse fibroblast cultures and changes seen in living cells. J Natl Cancer Inst 4: 165-212 
5. Hirano N, Onok SA, Inque A, Murkakami T, Takamuru H (1986) Replication of rat coronavirus in rat cell line, LBC. Arch Virol 85: 301-304

6. Hirano N, Takamuru K, Ono K, Murakami T, Fujiwara J (1986) Replication of sialodacryoadenitis virus of rat in LBC cell culture. Arch Virol 88: 121-125

7. Jacoby RO, Bhatt PN, Jonas AM (1975) Pathogenesis of sialodacryoadenitis in gnotobiotic rats. Vet Pathol 12: 196-209

8. Lussier G, Descoteaux J-P (1986) Prevalence of natural virus infections in laboratory rats and mice used in Canada. Lab Anim Sci 36: 145-148

9. Parker JC, Cross SS, Rowe WP (1970) Rat coronavirus (RCV): a prevalent, naturallyoccurring pneumotropic virus of rats. Arch Ges Virusforsch 31: 293-302

10. Percy D, Bond S, MacInnes J (1989) Replication of sialodacryoadenitis virus in mouse L-2 cells. Arch Virol 104: 323-333

11. Percy DH (1990) Experimental coronavirus infections in the Wistar rat: a comparison of lesions in rats inoculated with Parker's rat coronavirus and sialodacryoadenitis virus. (In preparation.)

12. Rothfels KH, Axelrad AA, Siminovich L, McIulloch EA, Parker RC (1959) The origin of altered cell lines from mouse, monkey and man as indicated by chromosome and transplantation studies. Can Cancer Conf 3: 189-214

13. Wojcinski ZW, Percy DH (1986) Sialodacryoadenitis virus-associated lesions in the lower respiratory tract or rats. Vet Pathol 23: 278-286

Authors' address: D. H. Percy, Department of Pathology, University of Guelph, Guelph, Ontario, Canada NIG2W1.

Received January 22, 1990 